\title{
Enterprise Valuation Analysis Based on Grey Prediction Model and Index Selection-A Case Study of Huayi Brothers Media Group
}

\author{
Na Luo ${ }^{1}$, Jiangrui Chen ${ }^{1}$, Lingyi Kong ${ }^{1} \&$ Yuanfeng Zhu ${ }^{1}$ \\ ${ }^{1}$ School of Jinan University, Guangdong, China \\ Correspondence: Na Luo, School of Jinan University, Guangdong, China. Tel: 86-137-5005-6336. E-mail: \\ 992796609@qq.com
}

Received: May 9, 2016

Accepted: May 24, 2016

Online Published: June 25, 2016

doi:10.5539/ijef.v8n8p11

URL: http://dx.doi.org/10.5539/ijef.v8n8p11

\begin{abstract}
Research on the investment value of enterprises has been a significant area, which the market investors and corporate decision-makers always pay much attention to. In this paper, Huayi Brothers Media Group, the leading enterprise of the film industry, is chosen as the research subject. The paper firstly targeted the difficulties of evaluating Huayi Brothers through analyzing its financial data. Then we used the improved grey prediction method as an absolute valuation model to estimate the cash flow, with relative valuation models, including PE, PB, PS and PEG, as supplements. From the results, we reached a conclusion that these two kinds of valuation models have a similar market value for Huayi Brothers at about 40 billion, which should be reliable when compared with the current average value, about 39 billion, evaluated by 13 official valuation mechanisms. What's more, the share price of Huayi Brothers in the bull market in 2015 is far higher than the reasonable range of value, and thus we advised that short-term investors have better not make an investment on Huayi Brothers until its share price is in a reasonable range.
\end{abstract}

Keywords: investment value, absolute valuation, relative valuation, GM model

\section{Introduction}

With the policies of our country, the domestic film and television industry has developed rapidly in recent years. In October 2009, the leading enterprise in the film and television industry, Huayi Brothers, has been listed, and after that many enterprises of this industry began to enter the capital market one after another. In addition, there are a lot of companies preparing to be listed. The rapid development of this industry listed companies has caused investors increasing concern about their investment value. The estimation of enterprise investment value refers to a means of judging the intrinsic value of the company stock by using a variety of valuation methods, based on various external factors affecting the value of enterprise and the analysis of corporate fundamentals, with full consideration to the company's growth.

In foreign research, Kaplan, Ruback (1995) took 51 high financing companies as examples in America from 1983 to 1989, and then compared the market value of these companies with its discounted value of free cash flow from prediction, with a conclusion that this method was of better accuracy than market comparison method. Jyoti Gupta, Alain Chevalier (2002) had discussed the difficulties of approaches based on benchmarking, the present value of economic value added, and the discounted value of the future free cash flows, which came to a conclusion that the real options were particularly suitable for the valuation of uncertainty, and gave the valuation results of two internet companies. Hans, Maik (2005) provided a comprehensive model to estimate corporate value based on customer-related cash flows and traditional financial metrics, and the result showed that incorporating customer-related drivers into financial valuation models made easier to assess the return on marketing investments. Doron Nissim (2013) examined the accuracy of relative valuation methods in the U.S. insurance industry, using price as a proxy for intrinsic value, and finally found that the gap between the valuation performance of forecasted EPS and the conditional price-to-book approach was relatively small during the last decade.

In domestic research, Zhang Lin (2005), through an index model equipped with comprehensive evaluation capacity, respectively used FUZZY comprehensive evaluation method, neural network and principal component analysis to make an evaluation on the intrinsic value of listed companies, and finally found that the nonlinear evaluation method was more reasonable and effective when assessing the investment value of listed companies, 
and put forward a threshold chosen model for listed companies at the same time. Li Yahui (2007) established the EVA model to analyze the effectiveness of EVA in Chinese security market empirically, and reached a conclusion that EVA could only be used for a limited range of business, so it was not suitable for financial institutions, cyclical companies, newly established companies, etc. Cao Jianxin, Huang Jialei (2008) compared the advantages and disadvantages of several methods about the valuation of listed companies. The result showed that the listed companies in different industries, with different financial status, needed to make best use of various valuation models to establish a comprehensive assessing system, and it was appreciated to combine at least one absolute valuation model with several relative valuation model for it may bring better results. Chen Jingwu, Lei Sheng (2008), using entropy weighting method and grey system theory to analyze the investment value of listed companies, found that this method was simple and feasible, and meanwhile had high reference value for investors and creditors. Wang Yaru (2012) analyzed the relative investment valuation methods, and then combining current development of Chinese stock market, established a value investment model based on growth relative valuation. The results show that PEG performs better in decision making than PE in the short, medium and long term, while taking specific periods and shareholding concentration into account, PBG has better decision-making effect than PB, and PSG also has better effect than PS in decision making. Huang Luwei (2014), selecting 30 technology stocks randomly from Shanghai Stock Exchange, used free cash flow model and price earnings ratio method to estimate the value of these companies, and then found that the absolute valuation method was more suitable for medium-term estimation while the relative valuation method was more suitable for short-term estimation.

Previous studies are mainly limited to single valuation method and lack of systematic comparison among different valuation methods. What's more, some existing researches even ignore the financial characteristics of listed companies in the film and television industry. Given the reasons above, this paper looks through the financial data about Huayi Brothers company between 2009 and 2015, and firstly analyzes the valuation difficulties, which lays the foundation for model selection. Secondly, according to the characteristics of few data, nonlinear and unknown distribution, we provide the grey prediction model for forecasting the free cash flow in absolute valuation method and test the results, while in relative valuation aspect, the index selection system is established and we choose the most stable index in the same industry as the basis of valuation. After that, we estimate the investment value respectively based on the two valuation methods. Finally, the paper carries out the reliability and contrast analysis on the results derived from two different valuation methods, and puts forward the conclusions and investment advice.

\section{Valuation Difficulties and Theoretical Models}

\subsection{Valuation Difficulties}

After comparing with other industries, we find that the film and television industry has several valuation difficulties as following.

Firstly, film and television companies are mostly with light asset that the ratio of intangible assets is lager, so it is difficult to estimate the value of company by using the net assets.

Table1. The comparison about intangible assets between the whole industry and the film and television industry

\begin{tabular}{ccc}
\hline Industry & Whole industry & Film and television industry \\
\hline The proportion of intangible assets against assets & $0.33 \%$ & $0.64 \%$ \\
The proportion of intangible assets against non-current assets & $0.63 \%$ & $1.28 \%$ \\
\hline
\end{tabular}

Secondly, the cash flow of film and television companies is unstable. There exist two reasons accounting for this phenomenon. On the one hand, the main products of this kind of companies are movies and TV shows, while the income of these two products is unstable. On the other hand, the cost and revenue of film and television often don't occur in the same year. 


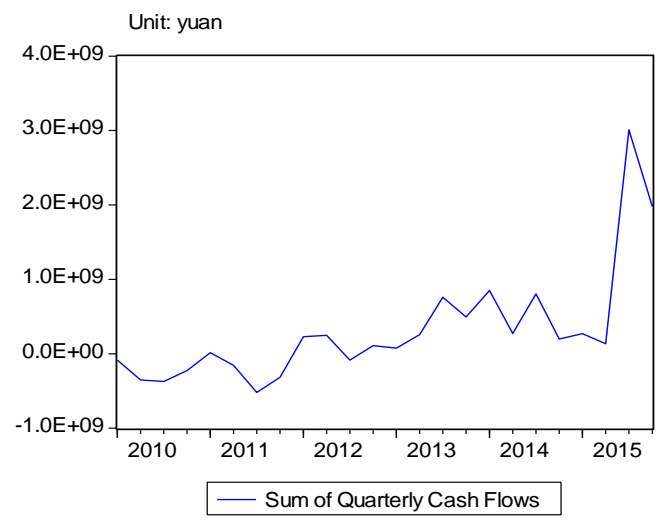

Figure 1. The quarter cash flow of Huayi Brothers between 2010 and 2015

Thirdly, there are few companies suitable for comparison.

Because the three difficulties in the valuation of film and television industry are so common that the valuating results conducted by different investment companies sometimes vary quite a lot. This paper firstly introduces the commonly used valuation methods, and then discusses its practical application range. After that the paper chooses the optimum method to carry out the valuation and presents the reliability test.

\subsection{The Theoretical Valuation Models}

The methods of company valuation mainly include the absolute valuation model, the relative valuation model and the real options model.

As for the absolute valuation model, the value of an enterprise depends on its ability to create cash flow in the future. This kind of method includes dividend discount model and free cash flow model. Because the dividends distributed by listed companies in China are few and unstable, it is not proper to use the dividend discount model to estimate these companies. Based on the reason above, in this paper, we use the free cash flow method to estimate the value of Huayi Brothers. During the process of valuation, the difficulty is how to predict the cash flow and choose the discount rate.

In the relative valuation model, the value of an enterprise is calculated by the similar indices of comparable companies. This method contains two assumptions. First, the value of the comparable companies is absolutely correct. Second, those comparable companies also have comparability in calculation. In fact, it is very hard to find the comparable companies which meet the assumptions above. In this paper, the first difficulty is solved by adopting the average in the film and television industry, and the second difficulty is settled by mean variance model.

Because our country only has index option, the real options model is not suitable for the valuation of the domestic listed companies. Therefore, the real options model is not introduced in this paper.

\subsubsection{The Absolute Valuation Method—Discounted Free Cash Flow Model}

Discounted free cash flow model believes that the value of a company is based on the sum of discounted value of all free cash flow in the future. According to the annual predicted free cash flow in the future, the model is divided into zero growth model, fixed growth model and non-fixed growth model.

$$
\mathrm{V}=\sum_{i=1}^{\infty} \frac{F C F F_{i}}{(1+W A C C)^{i}}
$$

Where $V$ stands for present value of the company, $F C F F_{i}$ stands for the fee cash flow of company at time $t$, and WACC stands for weighted average cost of capital.

In fact, when a company enters into a stable period after the rapid development, its growth rate is steady.

$$
\mathrm{V}=\sum_{i=1}^{n} \frac{F C F F_{i}}{(1+W A C C)^{i}}+\frac{F C F F_{n+1}}{(W A C C-g)(1+W A C C)^{n+1}}
$$

Where $\mathrm{FCFF}_{i}$ is the free cash flow of year $i$ during the rapid growth period, $F C F F_{n+1}$ is the free cash flow of 
the first year during steady growth period, and $g$ is the sustainable growth rate.

Step one: Calculate WACC. WACC represents weighted average cost of capital. We can define it as:

$$
W A C C=\frac{E}{\mathrm{~A}} \times \mathrm{K}+\frac{B}{E} \times \mathrm{B}(1-\mathrm{T})
$$

Where $\frac{E}{\mathrm{~A}}$ describes the ratio of equity to total assets, $\frac{B}{E}$ describes the ratio of debt to total assets.

And $T$ stands for tax rate, $B$ is the cost of debt (we can use the one-year bank loan interest rate instead of it), and $K$ is cost of equity, which can be estimated by the CAPM model of Markowitz (1952).

$$
\mathrm{K}=\mathrm{r}_{f}+\beta \times\left(r_{m}-r_{f}\right)
$$

Where $K$ describes the cost ratio of equity capital, $r_{f}$ is risk-free interest rate, $\beta$ is the beta coefficient of stock, $r_{m}$ is the expected rate of return on the market portfolio, and $r_{m}-r_{f}$ actually stands for market risk premium.

Step two: Calculate FCFF. As for the quantitative methods of free cash flow, different scholars have different ideas. Rappaport, Copeland, Cornell and other scholars have given their own quantitative formula of free cash flow. Let's take Copeland formula as an example.

$$
\mathrm{FCFF}=\mathrm{EBIT} \times(1-T)+D-A-B
$$

Where EBIT is the earnings before interest and tax, $T$ is the tax rate, $D$ is the depreciation, $A$ stands for the increased amount of capital expenditure, $B$ stands for the increased amount of working capital.

Step three: Calculate the sustainable growth rate $g$. In this paper, we choose the compound growth rate of the main business of Huayi Brothers between 2009 and 2015 as the company's future growth rate.

\subsubsection{The Improved Discounted Free Cash Flow Model}

1). The method of predicting future free cash flow

How to correctly predicted and calculate the cash flow is the key to the improved discounted free cash flow model. The most important problem is the financial data of the company is extremely little. At present, there are three kinds of predicting methods adopted by the academics and practitioners for this difficulty.

Table 2. The methods of predicting cash flow nowadays

\begin{tabular}{cc}
\hline Methods & Branches \\
\hline & Arithmetic Average Method \\
Time Series & Weighted Average Method \\
Predicting Method & Moving Average Method \\
& Exponential Smoothing Method \\
Correlated Factors & Unitary Linear Regression Method \\
Predicting Method & Multiple Linear Regression Method \\
Probability Analysis Predicting Method & Markov Prediction Method \\
\hline
\end{tabular}

However, these methods require large sample, linear characteristic, known distribution and other conditions, so under the circumstance of small sample, uncertainty, nonlinear characteristic and unknown distribution, the methods mentioned above are basically ineffective, while the grey prediction model can solve these problems properly.

Grey theory was put forward by Chinese famous professor Deng Julong (1982) and is universally recognized as a systematic theory in the whole world, which is a kind of innovative method for those small and partial information unknown systems. It now has been widely used in the prediction of different industries. What's more, grey theory always seeks the change rule through the collation of the original data, and then the grey sequence generates. It can weaken the randomness of the original data by claiming process and find certain regularity.

2). The grey prediction model

GM $(1,1)$ model is the most basic and widely used model in the grey system theory. 
Step one: Data detecting and processing. In order to ensure the reliability of the model, it is necessary to do some detecting and processing for the known data column. Assume that the reference data is $x^{(0)}=\left(x^{(0)}(1), x^{(0)}(2), \cdots, x^{(0)}(n)\right)$, and then calculate the stepwise ratio of the number sequence.

$$
\lambda(k)=\frac{x^{(0)}(k-1)}{x^{(0)}(k)} \quad(k=2,3, \cdots, n) .
$$

If all of the stepwise ratios $\lambda(k)$ fall in the range $X=\left(e^{-\frac{2}{n+1}}, e^{\frac{2}{n+1}}\right)$, the number sequence $x^{(0)}$ can be used as the model GM $(1,1)$ and then we can carry out the grey prediction for data. Otherwise, it is necessary to conduct transformation for the sequence $x^{(0)}$, with the purpose of making it fall in the range mentioned above, which means taking appropriate constant $c$ and then doing translation transformation.

$$
y^{(0)}(k)=x^{(0)}(k)+c \quad(k=2,3, \cdots, n) .
$$

So the stepwise ratio of the number sequence $y^{(0)}=\left(y^{(0)}(1), y^{(0)}(2), \cdots, y^{(0)}(n)\right)$ is

$$
\lambda(k)=\frac{y^{(0)}(k-1)}{y^{(0)}(k)} \in X \quad(k=2,3, \cdots, n) .
$$

Step two: Establish the GM $(1,1)$ model. We assume the known reference data column is $x^{(0)}=\left(x^{(0)}(1), x^{(0)}(2), \cdots, x^{(0)}(n)\right)$, and then conduct an accumulation to get the sequence of number.

$$
\begin{aligned}
x^{(1)} & =\left(x^{(1)}(1), x^{(1)}(2), \cdots, x^{(1)}(n)\right) \\
& =\left(x^{(1)}, x^{(1)}(1)+x^{(0)}(2), \cdots, x^{(1)}(n-1)+x^{(0)}(0)\right),
\end{aligned}
$$

Where $x^{(1)}(k)=\sum_{i=1}^{k} x^{(0)}(i) \quad(k=1,2, \cdots, n)$.

After that we calculate the mean series.

$$
z^{(1)}(k)=0.5 x^{(1)}(k)+0.5 x^{(1)}(k-1) \quad(k=2,3, \cdots, n),
$$

Namely $z^{(1)}=\left(z^{(1)}(2), z^{(1)}(3), \cdots, z^{(1)}(n)\right)$.

So we can establish the grey differential equation as below.

$$
x^{(0)}(\mathrm{k})+a z^{(1)}(k)=b \quad(k=2,3, \cdots, n)
$$

And the corresponding albinism differential equation is

$$
\frac{d x^{(1)}}{d t}+a x^{(1)}(t)=b
$$

Assume $u=(a, b)^{T}, Y_{t}=\left(x^{(0)}(2), x^{(0)}(3), \cdots, x^{(0)}(n)\right)^{T}$ and $B=\left[\begin{array}{cc}-z^{(1)}(2) & 1 \\ -z^{(1)}(3) & 1 \\ \vdots & \vdots \\ -z^{(1)}(4) & 1\end{array}\right]$, and then based on the least square

method, we can get the value of parameter estimation which makes $J(\hat{u})=\left(Y_{t}-B \cdot \hat{u}\right)^{T}\left(Y_{t}-B \cdot \hat{u}\right)$ achieve the minimum value. 


$$
\hat{u}=(\hat{a}, \hat{b})^{T}=\left(B^{T} B\right)^{-1} B^{T} Y_{t} .
$$

So we can work out the albinism differential equation and get

$$
x^{(1)}(k+1)=\left(x^{(0)}(1)-\frac{b}{a}\right) e^{-a k}+\frac{b}{a} \quad(k=1,2, \cdots, n-1) .
$$

Meanwhile, there exists $x^{(0)}(k+1)=x^{(1)}(k+1)-x^{(1)}(k) \quad(k=1,2, \cdots, n-1)$.

Step three: Test the predictive value.

First it is residual test. Let $\varepsilon(k)$ be the residual, and calculate

$$
\varepsilon(k)=\frac{x^{(0)}(k)-\hat{x}^{(0)}(k)}{x^{(0)}(k)} \quad(k=1,2, \cdots, n)
$$

If $\varepsilon(k)<0.2$, it can be considered to meet the general requirement, and if $\varepsilon(k)<0.1$, it can be considered to meet the high requirement.

Then it is turn to the deviation test of the stepwise ratio. We can calculate the stepwise ratio $\lambda_{0}(k)$ by the reference data $x^{(0)}(k-1)$ and $x^{(0)}(k)$, and work out the corresponding deviation value of the stepwise ratio by development coefficient $a$.

$$
\rho(k)=1-\left(\frac{1-0.5 a}{1+0.5 a}\right) \lambda_{0}(k)
$$

If $\rho(k)<0.2$, it can be considered to meet the general requirement, and if $\rho(k)<0.1$, it can be considered to meet the high requirement.

Step four: Give the prediction.

After obtaining the prediction free cash flow within a special time period through GM $(1,1)$ model, we can work out the predictive value correspondingly based on the fact.

\subsubsection{The Relative Valuation Model}

In the relative valuation model, the value of a company not only depends on the financial statements themselves, but also is influenced by the impact of supply and demand on the secondary market. Therefore, there are some differences in the results between the absolute valuation and the relative valuation. The relative valuation methods include PE ratio method, PB method, PS method and PEG method.

Based on the financial statements, the paper calculates the specified index of the company to be evaluated, for example, earnings per share, and then multiplied by the fix indicator such as PE, we get the estimated share price of the company. So it can be obtained the value of the company by multiplying the share price and the total number of stocks.

1). Price earnings ratio $(\mathrm{P} / \mathrm{E})$ method

Price earnings ratio $(\mathrm{P} / \mathrm{E})$ is the ratio of the market price of stock to its net income per share. The advantage is the ease of calculation. This is because it only requires the share price and current earnings situation of the company. This method can reflect the risk and growth characteristic of the company intuitively, but it can't be used when the return is negative. In addition, when the return changes particularly frequently, the price earnings ratio may change dramatically. The price earnings ratio is divided into static price earnings ratio and dynamic price earnings ratio. The expression is as follows: 


$$
K=\frac{P}{E}
$$

Where $K$ represents the static price earnings ratio, $P$ represents the current share price of the company, and $E$ represents the earnings per share of the company in the last year.

$$
K_{t}=\frac{P_{t}}{E_{t+1}}
$$

Where $K_{t}$ indicates dynamic price earnings ratio, $P_{t}$ indicates the current share price of the company, and $E_{t+1}$ indicates the company's earnings per share for the next fiscal year.

2). Price to book ratio $(\mathrm{P} / \mathrm{B})$ method

Price to book ratio $(\mathrm{P} / \mathrm{B})$ is the ratio of the market price of the stock to the book value per share. This index is relatively stable, for the reason that the book value is more stable than the earnings per share. Therefore, when the earnings per share is negative or changes frequently, the price to book ratio is more practical than the price earnings ratio, but the PB method is limited. For example, as for the price to book ratio of the light assets and the problem whether the current value of the company's asset has changed or nor, if the book still records the price to book ratio calculated by the original cost, it can't reflect the correct value of the company. The expression of price to book ratio is as follows

$$
M=\frac{P}{B}
$$

Where $M$ represents the price to book ratio, $P$ represents the price per share, and $B$ represents the book value per share of the company.

\section{3). Price to sales ratio (PS) method}

Sales revenue method regards the price to sales ratio (PS) as the indicator, which is the ratio of enterprise value and annual sales revenue. When using the PE and PB to carry out valuation, if the revenue and the book value are negative, these two methods are useless. In this situation, the investors can use the PS ratio to solve this problem, because the sales revenue will not influenced by the accounting policies adopted by the depreciation, inventory and non-recurring expenditures. However, if we only concerned sales revenue and ignore the cost control, depreciation and other factors when using the PS ratio, there are likely to make wrong judgements and evaluation. The expression of price to sales ratio is as follows

$$
\text { PS Ratio }=\frac{E V}{\text { Sales }}
$$

Where PS Ratio represents the price to sales ratio, EV represents the market value of the enterprise, and Sales represents the sales revenue.

\section{4). PEG method}

PEG (PE/Growth) method is a means of assessing the growth of a company, which is the ratio of the price earnings ratio to the growth rate. According to the annual growth rate, the earnings per share have different selection methods, but we generally take the growth rate of next year or the compound growth rate of next few years. Investors generally believe that PEG equal to 1 indicates the price earnings ratio compared with growth is relatively reasonable, PEG less than 1 indicates the price earnings ratio compared with growth is relatively low, and PEG larger than 1 indicates the price earnings ratio compared with growth is relatively high. Those companies with small PEG are suitable for investment. The expression of PEG is as follows.

$$
P E G=\frac{\frac{P E}{G}}{100}
$$

Where $P E$ represents the price earnings ratio, and $G$ represents the annual growth rate of return.

\section{The Valuation Results and Analysis}

\subsection{The Estimated Result of the Absolute Valuation Method}

Due to the low proportion of domestic stock dividend and its unpredictable characteristic, the paper uses the free cash flow model based on the grey prediction to carry out the valuation, instead of the dividend discount model. 


\subsubsection{Establish the Financial Data System}

The main financial data of Huayi Brothers is as follows,

Table 3. The main financial data of Huayi Brothers Unit: One hundred million yuan

\begin{tabular}{|c|c|c|c|c|c|c|c|c|c|}
\hline Year & $\begin{array}{l}\text { Total } \\
\text { asset }\end{array}$ & $\begin{array}{c}\text { Shareholders } \\
\text { equity }\end{array}$ & $\begin{array}{c}\text { The main } \\
\text { business income }\end{array}$ & Depreciation & EBIT & $\begin{array}{c}\text { Net } \\
\text { margin }\end{array}$ & $\begin{array}{c}\text { Increased working } \\
\text { capital }\end{array}$ & $\begin{array}{c}\text { Increased capital } \\
\text { expenditure }\end{array}$ & $\begin{array}{c}\text { Free cash } \\
\text { flow }\end{array}$ \\
\hline 2011 & 24.64 & 17.08 & 8.92 & 0.18 & 2.73 & 2.05 & -0.64 & 0.49 & -3.15 \\
\hline 2012 & 41.38 & 21.25 & 13.86 & 0.34 & 3.21 & 2.41 & 0.27 & 1.55 & 1.10 \\
\hline 2013 & 72.12 & 39.58 & 20.14 & 0.44 & 8.98 & 6.73 & -0.23 & 0.44 & 4.96 \\
\hline 2014 & 98.19 & 56.80 & 23.89 & 0.50 & 12.79 & 10.34 & 11.87 & 0.38 & 1.98 \\
\hline 2015 & 178.94 & 107.30 & 38.74 & 0.59 & 14.96 & 12.18 & -9.76 & -0.10 & 19.77 \\
\hline
\end{tabular}

Where the increase in working capital is equal to the difference of the working capital between this year and next year, and the working capital in a given year is equal to the difference of the liquid asset and the liquid debt in that year. Besides, the increase in capital expenditure is equal to the sum of the increase in the fixed assets, the increase in engineering materials and the increase in construction projects.

According to the data in Table 3, the valuation model of the free cash flow is:

$$
\mathrm{V}=\sum_{i=1}^{n} \frac{F C F F_{i}}{(1+W A C C)^{i}}+\frac{F C F F_{n+1}}{(W A C C-g)(1+W A C C)^{n+1}}
$$

\subsubsection{Estimate FCFF Based on the Grey Model}

Because Huayi Brothers was listed in October, 2009, the paper chooses the data between 2009 and 2015 as sample.

1). Calculate the data sequence $x_{k}$ by accumulation

Table 4. The data sequence $x_{k}$

\begin{tabular}{cccccccc}
\hline & 2009 & 2010 & 2011 & 2012 & 2013 & 2014 & 2015 \\
\hline $\begin{array}{c}\text { Cash flow } \\
\text { (One hundred million yuan) }\end{array}$ & 9.90 & -2.24 & -3.15 & 1.10 & 4.96 & 11.98 & 19.77 \\
\hline
\end{tabular}

$$
\mathrm{x}^{(1)}(k)=\left[\mathrm{x}^{(1)}(1), \mathrm{x}^{(1)}(2) \cdots, \mathrm{x}^{(1)}(n)\right]=9.90,-2.24,-3.15,1.10,4.96,1.98,19.77
$$

2). Determine the data matrix $X, Y$

$$
X=\left[\begin{array}{c}
-\frac{1}{2}\left[\mathrm{x}^{(1)}(1)+\mathrm{x}^{(1)}(2)\right] \\
-\frac{1}{2}\left[\mathrm{x}^{(1)}(2)+\mathrm{x}^{(1)}(3)\right] \\
\ldots \\
-\frac{1}{2}\left[\mathrm{x}^{(1)}(n-1)+\mathrm{x}^{(1)}(n)\right]
\end{array}\right]=\left[\begin{array}{c}
-8.8 \\
-7.2 \\
-7.3 \\
-10.3 \\
-18.8 \\
-34.7
\end{array}\right], \quad Y=\left[\begin{array}{c}
x^{(0)}(2) \\
x^{(0)}(3) \\
\ldots \\
x^{(0)}(n)
\end{array}\right]=\left[\begin{array}{c}
-2.24 \\
-3.15 \\
1.10 \\
4.96 \\
11.98 \\
19.77
\end{array}\right], \quad E=\left[\begin{array}{c}
1 \\
1 \\
1 \\
1 \\
1 \\
1
\end{array}\right]
$$

3). Calculate the parameter series a, u by least square method

$$
\begin{gathered}
\mathrm{Y}=\mathrm{aX}+\mathrm{uE} \\
\hat{a}=\left[\begin{array}{l}
a \\
u
\end{array}\right]=\left(X X^{T}\right)^{-1} \mathrm{X}^{T} \mathrm{Y}=\left[\begin{array}{l}
0.0414 \\
1.7693
\end{array}\right]
\end{gathered}
$$

4). Test the error

Compare $\hat{x}^{(0)}(k)$ with the original series, and get the average relative error by calculation is $c=11 \%$. The result is close to the third level of the grey theory, so it is available.

$5)$. Predict the future value through $\hat{x}^{(1)}(k)$ 
Let $k=7$, and get $\hat{x}^{(1)}(7)=39.14$. Restore $\hat{x}^{(10)}(7)=6.82$. Change the value of $k$ in turn, and get the value of other years.

6). Establish the metabolism model

The metabolism model is established by rolling out the value of the first period continuously and adding the value of the last period, thus we get the estimated value of future cash flow. The estimated results of the free cash flow in the next three years are as follows.

Table 5. The estimated results of the free cash flow of Huayi Brothers in the next three years (Unit: One hundred million yuan)

\begin{tabular}{cccc}
\hline & 2016 & 2017 & 2018 \\
\hline $\begin{array}{c}\text { Cash flow } \\
\text { (One hundred million yuan) }\end{array}$ & 6.82 & 10.30 & 5.57 \\
\hline
\end{tabular}

\subsubsection{Estimate the Weighted Average Cost of Capital and $g$}

1). Estimate WACC

$$
W A C C=\frac{E}{\mathrm{~A}} \times \mathrm{K}+\frac{B}{E} \times \mathrm{B}(1-\mathrm{T})
$$

$\frac{E}{\mathrm{~A}}$ and $\frac{B}{E}$ choose the average value between 2009 and 2015, namely $\frac{E}{\mathrm{~A}}=0.6, \frac{B}{E}=0.4$.

Where $T$ is the tax rate of the film and television company, namely $15 \%, B$ is the cost of debt, which can be replaced by the one-year interest rate of bank loan, namely $6.55 \%$, and $K$ is cost of equity, which can be estimated by the CAPM model of Markowitz (1952).

$$
\mathrm{K}=\mathrm{r}_{f}+\beta \times\left(r_{m}-r_{f}\right)
$$

Where $r_{f}$ is the risk-free interest rate, and this paper selects the compounded correction value of treasury rate, namely $3.05 \%, r_{m}$ is the expected rate of return on the market portfolio, $\beta$ is the beta coefficient of stock, which is the correlation coefficient of stock return and market return. Taken into account the simplicity of this paper, we give the results directly, namely $r_{m}=11.7 \%, \beta=1.4306$.

So

$$
\begin{gathered}
\mathrm{K}=3.05 \%+1.4306 \times(11.7 \%-3.05 \%)=15.42 \% \\
W A C C=0.6 \times 7.13 \%+0.4 \times 6.55 \times(1-15 \%)=11.48 \%
\end{gathered}
$$

2). Estimate the annual growth rate $g$

$11.74 \%$, the compound growth rate of main business from 2009 to 2015 , is being chosen as the future growth rate of the company in this paper.

\subsubsection{Estimate the Value of the Company and Test the Value}

Using the formula, we do a math with the estimated data

$$
\mathrm{V}=\sum_{i=1}^{\infty} \frac{F C F F_{i}}{(1+W A C C)^{i}}+\frac{F C F F_{n+1}}{(W A C C-g)(1+W A C C)^{n+1}}
$$

And then we get $V=40.867$ billion yuan.

Because there are 1.39 billion shares of the total equity, so the value of each share is 29.36 yuan, that is, the share price is $P=29.36$ yuan. The share price of the company is 28.59 yuan currently and has fluctuated between 23 and 63 yuan in recent years, so we can see an outstanding rationality of this method.

The estimated market value of Huayi Brothers is 40.867 billion, which should be reliable when compared with the current average value, 39.748 billion, evaluated by 13 official valuation mechanisms from wind's statistics. 


\subsection{The Estimated Result of the Relative Valuation Method}

First it needs to select the comparable companies, and then choose the relative valuation index, and then start to evaluate.

\subsubsection{Choose the Comparable Companies}

Given the difficulties when choosing the comparable companies and the high similarity in business within the same industry, the average value of listed companies in the industry is often regarded as the simulated comparable level, and then we compare it with the target company.

\subsubsection{Choose the Index}

Different industries have different intrinsic similarity index, so we should choose the indexes like PE, PB, based on different situations. Here the paper selects the proper index through comparison in the industry. The smaller of the volatility of PE in the industry is, the better the index is.PE is equal to the share price divided by earnings per share. If PE of each company behaves stable on mean and its standard deviation is very small, it means we can use this index for study. The results of different indexes in the film and television industry are as follows.

Table 6. Three indexes of the film and television industry

\begin{tabular}{lllll}
\hline Index & PE & PB & PS & PEG \\
\hline Mean & 40 & 4 & 18 & 35.82 \\
Standard deviation & 13.6 & 2.08 & 76.72 & 97.78 \\
Standard deviation/Mean & 0.34 & 0.52 & 0.36 & 0.278 \\
\hline
\end{tabular}

From Table 6, we can know that the standard deviation per mean of PEG in this industry is the smallest, that is, PEG has the smallest fluctuation. However, since the growth rate of operating profit in the past year reached $40 \%$, which is a pretty high level that it is difficult to achieve again in the future, the paper decides to use PE to evaluate.

According to this rule, we come to a conclusion as follows after the calculation of the indexes of the relative valuation and the predictability of fluctuation of the free cash flow.

Table 7. Choice of valuation methods in different industries

\begin{tabular}{lll}
\hline Industry & Characteristic & Method \\
\hline Traditional Industry & steady & PE, DCF \\
High-tech Industry & Unstable cash flow & PE \\
Retail Industry & Stable sales revenue & PS \\
Real Estate and Hotel Industry & High debt-asset ratio & RNAV(Revaluated Net Assets Value) \\
Resource & Large output and ownership & P/Reserve, Option Pricing \\
Operation Industry & Stable operation & EV/EBITDA \\
\hline
\end{tabular}

In different stages of an enterprise, the index we choose is also different.

Table 8 . The valuation method chosen by enterprises in different stages

\begin{tabular}{lll}
\hline Stage & Characteristic & Method \\
\hline Early & Unprofitable & PS, PE \\
Medium & Profitable & PE, PEG, DCF \\
Later & Stable in all aspects & PE, DCF \\
\hline
\end{tabular}

Taking all of the analysis above into consideration, it is the most suitable to use PE method to evaluate the market value of Huayi Brothers currently among all the relative valuation methods.

\subsubsection{Use PE to Carry Out the Valuation}

Because the mean of PE is 40 , and the standard deviation of it is 13.5 , with the confidence level of $68.26 \%$, we 
can achieve the confidence interval by subtracting the standard deviation from the mean or adding the former one to the latter one, so the confidence interval of PE is [26.4,53.6]. Assume that the earnings per share in the fourth quarter of 2015 is equal to 0.76 . According to the formula

$$
\mathrm{P}=\mathrm{PE} \times \mathrm{EPS}
$$

We obtain the predicted share price is 30 yuan, and the predicted range of the share price is from 20.06 yuan to 40.74 yuan.

In fact, the highest share price of Huayi Brothers in the past two years is 63.5 yuan in June 12, 2015, and the lowest one is 23 yuan in March 16, 2016. Therefore, the prediction is still of a certain accuracy

There are 1.39 billion shares of the total equity, so we can obtain the predictive value of the company is

$$
V=13.92 * 30=42.3 \text { billion }
$$

\subsection{Reliability Analysis}

In order to test the effectiveness of the valuation, the paper uses the data from 2009 to 2015 to estimate the value of the company iin2016, and then we compare the predictive value with the real value in 2016.

Table 9. The comparison between official data and predictive data

\begin{tabular}{ccccc}
\hline Method & $\begin{array}{c}\text { The share price in } \\
\text { 2016 (yuan) }\end{array}$ & $\begin{array}{c}\text { The value of the company in 2016 } \\
\text { (hundred thousand yuan) }\end{array}$ & $\begin{array}{c}\text { The official valuation } \\
\text { (hundred thousand yuan) }\end{array}$ & $\begin{array}{c}\text { The mean and range of } \\
\text { the share price (yuan) }\end{array}$ \\
\hline $\begin{array}{c}\text { The absolute } \\
\text { valuation method } \\
\begin{array}{c}\text { The relative } \\
\text { valuation method }\end{array}\end{array}$ & 29.36 & 408.57 & 397.48 & 28.89 \\
\hline
\end{tabular}

\section{The Analysis of Effectiveness}

\subsection{The Advantages}

1). Because there are many kinds of valuation methods, how to choose the suitable method for the company we study is particularly important and the decision should be based on the difficulties in the valuation of the company. Therefore, the paper firstly analyze the specific difficulties according to the financial data, which paves the way for selection and improvement of the subsequent valuation model

2). In the absolute valuation method, we use the grey prediction model to evaluate the free cash flow. In order to solve the problems of financial statement, such as few data, nonlinear characteristic, unknown information and so on, we select the grey prediction model from three common prediction methods to forecast the free cash flow, after taking into account the characteristic of small sample and unknown distribution. And the results are in line with our expectations.

3). In the relative valuation method, the paper establishes the chosen system of relative index. In order to solve the problem about how to quantitatively choose index, we build up a mean-standard deviation model. It not only provides a method for choosing the proper index in line with Huayi Brothers currently, but also is suitable for every industry, no matter what stage the company stays. Therefore, this method is of extensive applicability.

\subsection{The Disadvantages and Corresponding Improvement}

1). The data has dynamic nature. In this paper, we use the fixed beta of the last year to calculate the value of the risk beta, but the future data will change, resulting in the offset between some results and fact. Here we provide the improved method that we can make a dynamic prediction for beta by adopting the financial time series.

2). It is inevitable that there exists some deviations in the results, because the ray model is only suitable for the data with small-sample size and strong trend, and the film and television industry develops rapidly at present, which doesn't represent it can maintain the rapid growth in the future. To improve the reliability of the results, we can use the financial time series, neural network and other methods to carry out the comprehensive prediction for the free cash flow. Through the historical inspection and comparative analysis, it will obtain high-reliability results.

\section{Conclusions}

The paper makes a quantitative analysis of the company value and the share price, and then carries out the 
valuation from two angles, including the absolute valuation method and the relative valuation method, to estimate the market value of Huayi Brothers. During the process of valuation, we have taken into account the special assets, unstable cash flow, the long and unknown payback period, few companies suitable for comparison and other factors in the film and television industry. In the absolute valuation method, we use the grey prediction model to forecast the free cash flow. As for the relative valuation method, we firstly build up the chosen system of index to make a comprehensive analysis for comparable companies, and then we apply the confidence level to finish the valuation. In addition, the latter method is applicable to the analysis of each industry. The results obtained by the two different methods above have reached the similar conclusion, which indicates the market value of Huayi Brothers is around 40 billion. And it can be regarded as a reliable value because the current average value, evaluated by 13 official valuation mechanisms, is about 39 billion. Based on the market value of the company and the share price, we can achieve the reasonable range of fluctuation of the share price. Finally, we find that the share price of Huayi Brothers in the bull market in 2015 is far higher than the reasonable range of value, and thus we advised that short-term investors have better not make an investment on Huayi Brothers until its share price is in a reasonable range.

\section{References}

Doron, N. (2013). Relative valuation of U.S. insurance companies. Review of Accounting Studies, 182. http://dx.doi.org/10.1007/s11142-012-9213-8

Hans, H., \& Bauer, M. H. (2005). Customer-based corporate valuation: Integrating the concepts of customer equity and shareholder value. Management Decision, 433. http://dx.doi.org/10.1108/00251740510589733

Jianxin, C., \& Jialei, H. (2008). Research on the model of the absolute valuation method of listed Corporation in China. GD-HK-MO Market \& Price, 1, 40-43.

Jin, W., \& Lei, S. (2008). Then investment value evaluation of the listed Corporation based on Grey Relational Entropy. Journal of Hebei University of Technology, 37(1), 56-62.

Jyoti, G., \& Alain, C. (2002). Pertinence of real options approach to the valuation of internet companies. Operational Research, 22. http://dx.doi.org/10.1007/BF02936327

Kaplan, S. N., \& Ruback, R. S. (1995). The valuation of cash flow forecasts: An Empirical analysis. The Journal of Finance, 50(4), 1059-1093. http://dx.doi.org/10.1111/j.1540-6261.1995.tb04050.x

Lin, Z. (2005). The evaluation model and empirical research on the investment value of listed corporation. Jinan University, 2005.

Luwei, H. (2014). The absolute valuation method and relative valuation method: An Empirical Analysis Based on price earnings ratio and free cash flow model. Financial Times, 2, 107-108.

Yahui, L. (2007). Research on value evaluation of listed Corporation based on EVA. Southwestern University of Finance and Economics, 2007.

Yaru, W. (2012). Research on the relative valuation model based on Growth. Shanxi University of Finance and Economics, 2012.

\section{Copyrights}

Copyright for this article is retained by the author(s), with first publication rights granted to the journal.

This is an open-access article distributed under the terms and conditions of the Creative Commons Attribution license (http://creativecommons.org/licenses/by/3.0/). 